\title{
A CORREÇÃO DE FLUXO NA PROPOSTA PEDAGÓGICA DA REDE MUNICIPAL DE ENSINO DE PAULO LOPES/SC
}

\author{
Jéferson Silveira Dantas \\ Universidade Federal De Santa Catarina \\ clioinsone@gmail.com \\ Karoline Roda Da Silva \\ Universidade Federal De Santa Catarina \\ karoliiners@hotmail.com
}

\begin{abstract}
Resumo
Este artigo se propõe a discutir a concepção de correção de fluxo que se encontrava na proposta pedagógica da Rede Municipal de Ensino de Paulo Lopes/SC até 2017. Logo, o objetivo central do artigo é analisar por meio de pesquisa bibliográfica e documental o processo de ensino-aprendizagem na Classe de Correção de Fluxo concernente à Proposta da Rede Municipal em questão. Os resultados da pesquisa nos mostram que apesar de a iniciativa se basear na melhoria dos indicativos de aprendizagem e acolher aqueles estudantes que não se adaptaram ao ensino regular, os recursos orçamentários e a formação adequada dos trabalhadores em educação para tornar esse programa significativo ainda se mostravam ineptos.

Palavras-chave: Distorção idade-série. Repetência. Aceleração da aprendizagem. Fluxo escolar. Correção de fluxo.

\section{FLOW CORRECTION IN THE PEDAGOGICAL PROPOSAL OF PAULO LOPES/SC'S MUNICIPAL SCHOOL NETWORK}

\begin{abstract}
This article aims to discuss the conception of flow correction that was in the pedagogical proposal of Paulo Lopes/SC Municipal School until 2017. Therefore, the main objective of the article is to analyze through bibliographic and documentary research the teaching-learning process in the Flow Correction Class concerning the Proposal of the Municipal Network in question. The survey results show that while the initiative was based on improving learning standards and welcoming those students who did not adapt to mainstream education, the budgetary resources and adequate training of education workers to make this program meaningful were still showing inept.
\end{abstract}

Keywords: Age-grade distortion. Repetition. Acceleration of learning. School flow. Flow correction.

\section{LA CORRECCIÓN DE CAUDAL EN MARCHA DE EDUCATIVO RED DE MUNICIPAL PAULO LOPES ENSEÑANZA/SC}

\begin{abstract}
Resumen
Este artículo tiene como objetivo discutir el concepto de corrección de flujo que estuvo en la propuesta pedagógica de la Escuela Municipal de Paulo Lopes/SC hasta 2017. Por lo tanto, el objetivo principal del artículo es analizar mediante investigación bibliográfica y documental el proceso de enseñanza-aprendizaje en la clase de corrección de flujo en relación con la propuesta de la red municipal en cuestión. Los resultados de la encuesta muestran que, si bien la iniciativa se basó en mejorar los estándares de aprendizaje y dar la bienvenida a aquellos estudiantes que no se adaptaron a la educación general, los recursos presupuestarios y la capacitación adecuada de los trabajadores de la educación para que este programa sea significativo todavía se muestran inepto.
\end{abstract}

Palabras clave: Distorsión por grado de edad. Repetición. Aceleración del aprendizaje. Flujo escolar. Corrección del flujo.

Cidadania em Ação; Revista de Extensão e Cultura, Florianópolis (SC), v. 3, n. 2, jul./dez.2019. 


\section{INTRODUÇÃO}

Dentre os diversos fundamentos teóricos que compõem a História da Educação, podemos evidenciar que os problemas relativos à repetência e à evasão escolar surgiram, concomitantemente. Desse modo, já fazendo parte do cenário educacional em nível nacional (contudo, não de forma naturalizada, mas compreendida aqui como uma construção histórica), esses impasses tornaram-se focos de estudos, especialmente nas últimas décadas. Para tanto, por meio de pesquisa bibliográfica e documental, apontar-se-ão os autores que desde a década de 1930 vêm discutindo esta problemática educacional (DUARTE, 2005).

Assim, foi somente a partir da década de 1990, por meio da Lei n ${ }^{\circ}$ 9.394, de 20 de dezembro de 1996, que se estabelecem as Diretrizes e Bases da Educação Nacional (LDBEN), definindo legalmente a possibilidade de aceleração dos estudos para estudantes com atraso escolar, ou seja, deu-se início às políticas de aceleração da aprendizagem. Em tal contexto, em 1997, o Ministério da Educação (MEC) introduziu o Programa de Aceleração da Aprendizagem nas redes, cujo objetivo era corrigir a distorção do fluxo escolar. As escolas brasileiras incluíram em seus projetos políticos e pedagógicos as Classes de Correção de Fluxo, cada qual com especificidades em relação à aplicação metodológica desses programas. Para tanto, destacaremos alguns estados brasileiros que fizeram a adesão ao Programa, bem como salientaremos alguns municípios do estado de Santa Catarina, delimitando para o nosso foco de estudo, ou seja, o município de Paulo Lopes/SC. Nesse contexto estudaremos a proposta de Correção de Fluxo implementada através do Programa Classe de Aprendizagem para Inserção Social (CAIS), instituído na Escola Básica Dr. Ivo Silveira (E. B. Dr. Ivo Silveira) no ano de 2007, a partir de reuniões de professores e conselhos de classe realizados em 2006. A Correção de Fluxo na Proposta Pedagógica da Rede Municipal de Ensino de Paulo Lopes era composta apenas por uma turma, ou seja, pelo programa CAIS, classe esta não-seriada, abrangendo aproximadamente 20 estudantes, os quais eram indicados pelo Conselho de Classe, uma vez que não vinham obtendo aprovações nas classes regulares de $5^{\mathrm{a}}$ à $8^{\mathrm{a}}$ séries.

Posteriormente, faremos uma contextualização sobre a instituição de ensino que abrigava o Programa CAIS. Com esse escopo, especificaremos a localização da E. B. Dr. Ivo Silveira, bem como sua história enquanto instituição de educação desde seu ano de fundação. Ainda visando descrever uma conjuntura do foco dessa pesquisa, analisaremos a Proposta Curricular da Rede Municipal de Ensino de Paulo Lopes, bem como o Projeto Político Pedagógico da E. B. Dr. Ivo Silveira e, por fim, o Projeto do Programa CAIS. Para 
tanto, traremos alguns autores como Kramer (1997), Caetano e Diógenes (2010), Veiga (2002), Veiga (2007) e Libâneo (2004), com o intento de evidenciarmos o que de fato deve ser considerado essencial em um Projeto Político Pedagógico e a sua função enquanto documento norteador do trabalho escolar.

Com relação ao Projeto do Programa CAIS tivemos a ambição de identificar quais os objetivos pedagógicos previstos pela Rede Municipal de Ensino de Paulo Lopes/SC a partir da implementação da proposta de Correção de Fluxo, especificando a base legal municipal e nacional que asseguram a criação desse Programa, bem como a sua organização e a composição do corpo docente que atua no CAIS. Também faremos menção à Proposta Curricular com vistas para a Educação de Jovens e Adultos (EJA), uma vez que o Projeto do programa CAIS prevê essa modalidade de ensino, com os seus respectivos recursos pedagógicos aí inseridos. Para teorizar essa temática pesquisamos autores que discutem a Educação de Jovens e Adultos (EJA) como Arroyo (2005), Di Pierro et. al. (2001), Furini et. al. (2011) e Laffin (2010).

Mais adiante, buscaremos compreender como se dá a avaliação dos estudantes inseridos no Programa CAIS, abordando aspectos da perspectiva de avaliação em larga escala e avaliações por meio de pareceres descritivos, bem como os fatores que se relacionam com a formação continuada de professores, pontos esses que são considerados nessa pesquisa como o primeiro passo para uma educação pública de qualidade.

\section{BREVE HISTÓRICO DA ORIGEM DAS POLÍTICAS DE ACELERAÇÃO DA APRENDIZAGEM}

Os estudantes do Ensino Fundamental, do Ensino Médio e do Ensino Superior, precisam cumprir, de acordo com o Artigo $24^{1}$ da Lei 9.394/1996 - que estabelece as Diretrizes e Bases da Educação Nacionais (LDBEN) - 200 dias letivos anuais ou no mínimo, 800 horas-aula. No entanto, mesmo com essa carga horária, nem todos conseguem atingir a aprovação desejada nas disciplinas, o que os impossibilita de avançar no próximo ano. Essa problemática acaba por ocasionar a repetência e, consequentemente, a distorção idade/série,

\footnotetext{
${ }^{1}$ Art. 24. A Educação Básica, nos níveis fundamental e médio, será organizada de acordo com as seguintes regras comuns: I - a carga horária mínima anual será de oitocentas horas, distribuídas por um mínimo de duzentos dias de efetivo trabalho escolar, excluído o tempo reservado aos exames finais, quando houver. (BRASIL, 2016a, p. 7).
} 
que por sua vez é conceituada da seguinte maneira, de acordo com o site Educabrasil Dicionário Interativo da Educação Brasileira² (2001):

É a defasagem entre a idade e a série que o aluno deveria estar cursando. Essa distorção é considerada um dos maiores problemas do ensino fundamental brasileiro, agravada pela repetência e o abandono da escola. Muitos especialistas consideram que a distorção idade-série pode ocasionar alto custo psicológico sobre a vida escolar, social e profissional dos alunos defasados.

Assim, a Educação de qualidade e o seu acesso são um direito constitucional e um dever do Estado, previsto no artigo $206^{3}$ da Constituição Federativa do Brasil de 1988. Nesse sentido, a progressão nos estudos e a aprendizagem do indivíduo são os objetivos dos processos de escolarização, e, para que isso se efetive, é necessário que se leve em consideração o tempo de aprendizagem dos estudantes, que não é igual para todos. Logo, foram criadas por iniciativa do Estado as Classes de Correção de Fluxo ou de Aceleração da Aprendizagem como uma forma de solucionar o problema da defasagem dos estudantes que estavam em um ano que não correspondia à sua idade. Como ressalta Marochi (2000, p. 134):

Em nosso país, muito se fala em garantir o acesso à escola, mas todos sabemos que o grande desafio consiste em garantir o retorno daqueles que abandonaram os bancos escolares, a permanência depois do ingresso e ainda o sucesso, representado pela conclusão da educação básica por toda a população, com ricas e variadas aprendizagens, essenciais para o exercício da cidadania, possibilitando-lhe o prosseguimento dos estudos.

Para melhor entender tal questão, vamos fazer um apanhado geral do percurso da educação no que se refere ao âmbito das Classes de Correção de Fluxo (CCF). Começaremos então com as autoras Parente e Lück (2004, p. 14): "Sabe-se, por exemplo, que desde o primeiro Censo Educacional brasileiro, em 1932, registrava-se o ciclo da repetência já na $1^{\text {a }}$ série do Ensino Fundamental de cerca de $60 \%$ do alunado. O acesso à escola era de $60 \%$ da população escolarizável”.

\footnotetext{
${ }^{2}$ MENEZES, Ebenezer Takuno de SANTOS, Thais Helena dos. Dicionário Interativo da Educação Brasileira - Educabrasil. São Paulo: Midiamix, 2001. Disponível em: <http://www.educabrasil.com.br/distorcao-idadeserie/>. Acesso em: 01 de fev. 2016.

${ }^{3}$ Art. 206. O ensino será ministrado com base nos seguintes princípios: I - igualdade de condições para o acesso e permanência na escola; II - liberdade de aprender, ensinar, pesquisar e divulgar o pensamento, a arte e o saber; III - pluralismo de ideias e de concepções pedagógicas, e coexistência de instituições públicas e privadas de ensino; IV - gratuidade do ensino público em estabelecimentos oficiais. (BRASIL, 2016b, p. 104)
} 
Na década de 1930 a educação passou a ser reconhecida como uma questão nacional. Logo, em 1932, aconteceu o "Manifesto dos Pioneiros da Educação Nova", movimento da elite intelectual formada por Lourenço Filho, Fernando de Azevedo, Anísio Teixeira, Afrânio Peixoto, Roquette Pinto, Delgado de Carvalho, Hermes Lima, Cecília Meireles, dentre outros signatários, os quais almejavam a consolidação de uma visão que atendesse a possibilidade de interferir na organização da educação. Conforme o Instituto Nacional de Estudos e Pesquisas - INEP (1944, p. 567):

[...] o Manifesto dos Pioneiros da Escola Nova expressou um grande entusiasmo pela educação quando então se reuniram grandes nomes da área do século 20. Esse movimento de educadores surgiu dentro da Associação Brasileira de Educação (ABE) e resultou em um documento assinado por 26 signatários. Foi um grande acontecimento que marcou a história da educação brasileira, com grande repercussão em nossos meios educacionais e culturais.

Essa elite intelectual tinha também, como um de seus principais propósitos, a construção de uma nova política educacional que deveria ser única e embasada cientificamente, e ainda reivindicavam a criação de uma instituição pública para promover o desenvolvimento da educação. Portanto, "as diretrizes firmadas no manifesto influenciaram o texto da Constituição de 1934 que consagrou o Conselho Nacional de Educação, atribuindo-lhe como principal função a de elaborar o Plano Nacional de Educação" (PEREIRA; FELIPE; FRANÇA, 2006, p. 10).

Assim, a Constituição de 1934 foi criada estabelecendo que a educação era um direito de todos e dever da família e dos poderes públicos e, a partir desse momento, a educação passou a ser uma questão nacional, cabendo à União estabelecer as suas Diretrizes. Como afirma Vasconcelos (2006, p.8):

Ao tornar-se questão nacional são iniciadas algumas medidas de cunho compensatório aos problemas acumulados pela educação brasileira. Para o combate ao analfabetismo, provocado pela falta de oportunidade de acesso e pela evasão escolar nos primeiros anos de escolarização, é criado o ensino primário supletivo com duração de dois anos, destinado aos que não tiveram oportunidade de frequentar a escola na idade adequada. Ao atendimento dos alunos com fraco desempenho na passagem do curso primário para o ginásio, este último instituído com a reforma educacional sob o comando de Gustavo Capanema, foi organizado o ensino primário fundamental sob duas modalidades: o ensino primário elementar e o ensino complementar, de apenas um ano, acrescentado ao curso primário elementar.

Por volta de 1946, iniciaram-se os debates em torno da Lei de Diretrizes e Bases da Educação Nacional. Mas, foi na década de 1950, que o setor econômico ou produtivo começa a se interessar pelas pesquisas em educação, como destaca Fernandes (2004, p. 4):

Cidadania em Ação; Revista de Extensão e Cultura, Florianópolis (SC), v. 3, n. 2, jul./dez.2019. 
A década de [19]50, no Brasil, marcada pelo espírito desenvolvimentista, não suportaria níveis de reprovação tão elevados. É ao final dessa década e início da década seguinte que estudos econômicos passam a influenciar as pesquisas em educação. Estudos inspirados na teoria do capital humano reforçam a ideia de educação como investimento, formação de recursos humanos, retratando uma forte relação entre educação e mercado de trabalho.

Porém, somente mais tarde, em 20 de dezembro de 1961 é que foi a promulgada a Lei 4.024/1961, que fixava as Diretrizes e Bases para a Educação Nacional (VASCONCELOS, 2006). Mais adiante, em 1971 a legislação precisou, mais uma vez, se moldar à condição política que o país se encontrava, ou seja, a ditadura civil-militar (19641985). Por conseguinte, os avanços progressivos foram criados a partir da Lei 5.692 de 11 de agosto de 1971, artigo 14, parágrafo $4^{\circ}$, a qual estabelecia o direito de: "Verificadas as necessárias condições, os sistemas de ensino poderão admitir a adoção de critérios que permitam avanços progressivos dos alunos pela conjugação dos elementos idade e aproveitamento" (BRASIL, 2016c).

Oliveira (1999 apud PRADO, 2000, p. 1), relata que Lourenço Filho observou o problema da repetência em 1954 e Lauro de Oliveira Lima também constatou em 1964; a Comissão MEC/USAID chegou à mesma conclusão em 1968, e ainda Zaida Brandão e suas colaboradoras analisaram os debates sobre a repetência nacional e internacional em 1983. Até a década de 1980 poucas foram as iniciativas para construção de políticas públicas que direcionassem o foco para os estudantes reprovados e com sucessivos 'fracassos', e embora em 1980 o nível de repetência tenha baixado para 50\% (verificando-se decréscimo de $10 \%$ nesse período comparado a 1920) ainda assim era preocupante (PARENTE; LÜCK, 2004).

A partir da Conferência Mundial sobre Educação para Todos, que aconteceu em 1990, em Jomtien, na Tailândia - evento no qual foi elaborada uma Declaração que definia novas análises sobre as necessidades básicas de aprendizagem, tendo como objetivo estabelecer compromissos mundiais para assegurar à população os conhecimentos básicos e necessários, organizados pelos executivos da $\mathrm{UNICEF}^{4}$, do Programa das Nações Unidas

\footnotetext{
${ }^{4}$ Fundo das Nações Unidas para a Infância.
} 
para o Desenvolvimento (PNUD), da Organização das Nações Unidas para Educação, Ciência e Cultura (UNESCO) e do Banco Mundial (BM) -, o Brasil responsabilizou-se em erradicar o analfabetismo e melhorar os índices de aprendizagem na Educação Básica. Portanto, instituiu algumas medidas, planos e políticas governamentais como o Plano Decenal de Educação para Todos ${ }^{5}$, o Plano Político Estratégico ${ }^{6}$ e a promulgação da LDBEN 9.394/1996.

Deste modo, podemos considerar como uma das fortes influências para o surgimento das medidas e programas para corrigir o índice de defasagem e repetência no Brasil a visita de Henry Levin no país, como bem relata Prado (2000, p. 53):

\begin{abstract}
A título de ilustração, é interessante citar uma experiência externa que sem dúvida exerceu influência sobre o pensamento de alguns educadores brasileiros: o Programa Accelerated Schools, concebido na Universidade de Stanford e iniciado em 1986 no Estado da Califórnia. O Programa das Escolas Aceleradas tem em vista o sucesso escolar de alunos em situação "de risco". A visita ao Brasil, em 1992, de um de seus principais criadores, Henry Levin, possibilitou a disseminação da idéia das escolas aceleradas, especialmente por meio da publicação de um de seus artigos sobre o assunto.
\end{abstract}

Nesse contexto, há de se considerar que a ideia não era tão inovadora quanto parecia, ela já existia há algum tempo no Brasil e, mais ainda, internacionalmente. Vários autores, tal como Mainardes (1999; 2000) e Barreto (1999), já se debruçaram em cima dos estudos sobre a origem das políticas referentes à implantação de propostas de aceleração, correção, e etc., e como resultado de suas pesquisas, descobriram que essas propostas já haviam sido anunciadas, pela primeira vez, ainda na década de 1920 (FERNANDES, 2004).

Além de tudo, como Duarte (2010, p. 3-4) bem afirma:

Na década de 1980, uma das experiências mais conhecidas foi o Ciclo Básico de Alfabetização, que na verdade a idéia é parecida com a aceleração da aprendizagem, porém o Ciclo Básico de Alfabetização se antecipava à aceleração da aprendizagem, onde o aluno que era matriculado nessas classes tinha a idade adequada para a série correspondente, não apresentado assim a distorção idadesérie.

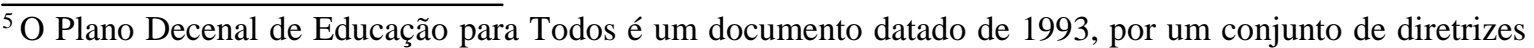
políticas voltado para a recuperação da escola fundamental no país. [...] O seu objetivo mais amplo é assegurar, até o ano 2003, a crianças, jovens e adultos, conteúdos mínimos de aprendizagem que atendam às necessidades básicas da vida na atualidade (MENEZES; SANTOS, 2001).

${ }^{6}$ Planejamento do Governo Federal que abrangeu o período de 1995 à 1998 que, além dos acordos firmados no Plano Decenal, concebeu mecanismos importantes para a implantação de uma educação de qualidade (PRADO, 2000).
} 
Em outras palavras, o Ciclo Básico de Alfabetização era como se fosse uma prevenção para evitar os casos de repetência. Mais tarde então, os Ciclos de Alfabetização tiveram algumas mudanças e, em 1997, o MEC introduziu o Programa Aceleração da Aprendizagem.

Porém, deve se levar em conta ainda que o projeto educacional estadunidense interferiu de alguma forma na concepção dos educadores brasileiros, até que na década de 1990 ficou prevista, com a promulgação da Lei n 9.394, de 20 de dezembro de 1996 (LDB), a possibilidade de aceleração dos estudos para estudantes que se encontravam em situação de defasagem idade/série; a LBDEN acabou por incentivar os sistemas de ensino a elaborar projetos e planejamentos que auxiliassem esses estudantes com atraso escolar, estabelecendo a aceleração dos estudos no artigo 32, parágrafo segundo, ou seja, deu-se origem às Políticas de Aceleração da Aprendizagem no Brasil, as quais têm como comprometimento o progresso e o desenvolvimento da aprendizagem daqueles estudantes que não conseguiram acompanhar o ensino regular.

Ainda vale ressaltar que a LDBEN considera que a progressão continuada é uma das formas de assegurar a permanência do aluno em situação de defasagem idade/ano nas instituições de educação escolar. Como indica o artigo 23 da Lei nº 9.394/1996:

A educação básica poderá organizar-se em séries anuais, períodos semestrais, ciclos, alternância regular de períodos de estudos, grupos não seriados, com base na idade, na competência e em outros critérios, ou por forma diversa de organização, sempre que o interesse do processo de aprendizagem assim o recomendar. (BRASIL, 2006a, p. 8).

Para pôr em prática os comprometimentos assumidos nas conferências internacionais, em 1997 o Ministério da Educação (MEC) introduziu o Programa de Aceleração da Aprendizagem nas redes de ensino objetivando a correção na distorção do fluxo escolar. Assim, as Classes de Correção de Fluxo foram incorporadas aos projetos pedagógicos das escolas brasileiras com nuances diferenciadas de aplicação metodológica. O MEC, então, começou a liberar recursos, com a condição de apresentação de projetos pelos municípios, os quais apresentavam alto índice de defasagem, para fazer um melhor encaminhamento dos estudantes aos anos escolares correspondentes à sua idade cronológica, através de metodologias pedagógicas alternativas e muitas vezes em classes não seriadas.

No estado de Santa Catarina essas Políticas apareceram em 1997 em função da introdução desse Projeto pelo MEC, durante o governo de Fernando Henrique Cardoso 
(1995-2002). Nesse mesmo ano começou a se defender publicamente o incentivo às escolas públicas para que aderissem ao Programa de Aceleração da Aprendizagem como forma de solucionar o problema da defasagem idade-ano/série. Desse modo, em 1997, como afirmam Hanff, Barbosa e Koch (2002, p. 30):

[...] chegam em Santa Catarina, as classes de aceleração embaladas na denúncia do fracasso escolar das escolas públicas, do número de reprovações e multirreprovações, pela influência direta e indireta de experiências realizadas em outros estados brasileiros e, principalmente, pela pressão exercida pelo governo federal e órgãos internacionais na implantação do Projeto, com base na Lei 9.394/1996.

No entanto, foi somente em 1998 que a rede estadual de Santa Catarina aderiu ao Projeto "Classes de Aceleração". Iniciou-se convidando as escolas estaduais para participar do projeto, algumas aceitaram no mesmo ano, e outras em 1999. "O processo de implantação em cada escola estadual sofreu muitas variações tanto na seleção dos alunos e composição dos níveis, como na escolha dos professores e até das diretrizes pedagógicas" (HANFF; BARBOSA; KOCH, 2002, p. 32). Ainda, de acordo com esses autores, podemos dizer que as instituições que aderiram procederam basicamente nos seguintes princípios:

As escolas, inicialmente, procederam a listagem dos alunos em situação de defasagem e em situação de reprovação. A partir daí, indicou-se o grupo de alunos que deveria ser incluído nas classes de aceleração. A inserção nas classes foi, entretanto, um processo de opção de cada aluno, pais ou responsável.

Sendo assim, a escola identificava quais eram os estudantes que estavam em situação de distorção idade/ano/série e logo o indicava para ser incluído nessas classes, porém deixava-se livre para o próprio estudante, os pais ou responsáveis decidirem se queriam ou não que ele fosse inserido nesse ambiente.

Convém abordar também que no ano de 2011, as GEREDs (Gerências Regionais de Educação) de Santa Catarina começaram a realizar um levantamento quantitativo com a intenção de identificar o número de estudantes com idade acima de 13 anos e que ainda se encontravam cursando as $5^{\mathrm{a}}$ séries $/ 6^{\circ}$ anos do Ensino Fundamental na rede estadual de educação. Diante dos dados elevados com base nos estudantes com defasagem idade/ano/série, a Secretaria de Estado da Educação de Santa Catarina (SED), considerou válida a oferta de um atendimento diferenciado para esses estudantes, considerando a conclusão do Ensino Fundamental em um ano. Desse modo, foi criado o "Programa de correção de fluxo idade/série: recuperação dos saberes”. Este Programa tinha como objetivo corrigir a defasagem idade/ano/série completamente e focava as habilidades de leitura, produção escrita, oral e cálculo. E assim, no ano de 2012 os estudantes puderam cursar o 
$6^{\circ}, 7^{\circ}$ e $8^{\circ}$ anos e, no ano seguinte, 2013, ingressar no Ensino Médio. (GRIS; TONDIN, 2015). Outras iniciativas com o mesmo objetivo, o de corrigir o fluxo escolar, também surgiram com a implementação do Programa Aceleração da Aprendizagem pelo MEC. Um exemplo é o Programa Acelera Brasil que, por iniciativa do Instituto Ayrton Senna (IAS) e com o apoio do Fundo Nacional de Desenvolvimento da Educação (FNDE/MEC) e a Petrobras foi criado em 1997. Realizou suas atividades em 15 municípios no mesmo ano de sua criação; um ano depois atendeu a24 municípios, e em 2000, atendeu também os estados do Espírito Santo e Goiás (LALLI, 2000).

De acordo com a Psicóloga do IAS, Viviane Senna Lalli (2000, p. 145):

[...] trata-se de um programa de correção de fluxo escolar - a aceleração da aprendizagem é apenas uma estratégia para atingir o objetivo maior; trata- se de uma intervenção nas políticas educacionais, que tem como objetivo eliminar a cultura da repetência nas escolas, não de mera intervenção pedagógica; o programa baseia-se em concepção e materiais testados previamente (o piloto foi testado no Maranhão, em 1995); a estratégia e os materiais vêm provando ser aderentes à realidade para a qual foram desenvolvidos; os professores contam com supervisão e assistência técnica permanente; o Programa possui mecanismos de acompanhamento, controle e avaliação externa e, com isso, vem se aprimorando ao longo do tempo.

Logo, entendendo que o município de Paulo Lopes faz parte da Região da Grande Florianópolis, vamos também situar o ano de adesão do Programa pela capital de Santa Catarina:

Na Rede Municipal de Ensino de Florianópolis a implantação ocorreu em 1999, em 8 escolas, e adveio da existência de índices significativos de reprovação e evasão escolar e consequentemente da existência de alunos em situação de defasagem idade-série e da possibilidade de implantação das classes de aceleração proposta pelo MEC. (HANFF; BARBOSA; KOCH, 2002, p.34)

Além de Florianópolis, em Santa Catarina houve outros municípios que também implementaram Programas com a mesma premissa dos citados anteriormente, como Itajaí, que contemplou o Programa Acelera Brasil em 1998.Nesse período a defasagem idade/ano no município oscilava em 14\%. O Programa era coordenado também pelo Instituto Ayrton Senna, apoiado pelo Centro de Ensino Tecnológico de Brasília (CETEB) e pela Petrobras, e quanto à avaliação contavam com a Fundação Carlos Chagas. Já no município de Balneário Camboriú, a ideia de programas semelhantes aos referidos foi aderida em 1999, mas esse por sua vez, era coordenado pela Secretaria Municipal de Educação (SCHLINDWEIN; PETRI; 2016).

No que tange à Rede Municipal de Ensino de Paulo Lopes/SC, com a proposta do Programa CAIS - Classe de Aprendizagem para Inserção Social, as/os docentes da Escola 
Básica Dr. Ivo Silveira, unidade localizada no bairro Penha, no município de Paulo Lopes, refletiam a respeito do processo de ensino aprendizagem daqueles estudantes que vinham apresentando sucessivas repetências na $5^{\mathrm{a}}, 6^{\mathrm{a}}, 7^{\mathrm{a}}$ e $8^{\mathrm{a}}$ série, que hoje corresponderiam ao $6^{\mathrm{o}}$, $7^{\circ}, 8^{\circ}$ e $9^{\circ}$ anos, respectivamente. Desse modo, no ano de 2007, como uma estratégia de intervenção pedagógica, cuja metodologia alternativa objetivava a valorização da diversidade e a elevação da autoestima de alunos e alunas que o ensino regular não vinha considerando as necessidades, expectativas e desejos dos mesmos; a Secretaria Municipal de Educação, baseada na resolução 01/2007 do Conselho Municipal de Educação, instituiu a proposta do Programa CAIS (PAULO LOPES, 2007).

A Proposta Pedagógica do CAIS caracterizava-se como uma ação específica comparada à Proposta da Escola em que estava inserida, com o intuito de corrigir a situação de defasagem idade-ano, partindo de estudos e de aprendizagens significativas. Além de objetivar a regularização do fluxo no Ensino Fundamental, a Proposta preocupava-se demasiadamente com a reconstrução da autoestima do seu sujeito-alvo, o estudante, sendo que a mesma, de acordo com Brander (1994 apud SCHLINDWEIN; PETRI; 2004, p. 4).

[...] é a confiança em nossa capacidade de pensar e enfrentar os desafios básicos da vida. A confiança em nosso direito de ser feliz, a sensação que temos de valor, de que somos merecedores, de que temos o direito de expressar nossas necessidades e desejos e de desfrutar os resultados de nossos esforços.

Os estudos mais recentes encontrados a respeito das Políticas de Correção de Fluxo e que tinham alguma proximidade com o tema da presente pesquisa foram o artigo de Lygia S. Viégas e Marilene P. R. Souza, intitulado Promoção automática nos anos 1950: a experiência pioneira do Grupo Experimental da Lapa (São Paulo), que foi publicado no ano de 2012; uma monografia de especialização da autora Ana Carolina França de Oliveira, cujo título é Perfil do Profissional que Atua com Jovens em Situação de Vulnerabilidade Social e ou Risco do Programa da Correção de Fluxo da Rede Pública Estadual de Ensino, que data o ano de 2013; e um Trabalho de Conclusão de Licenciatura, do Curso de Ciências Sociais, do Centro de Filosofia e Humanas (CFH) da Universidade Federal de Santa Catarina (UFSC) com título Repetência e distorção idade-série nas escolas públicas de Ensino Fundamental de Santa Catarina: um estudo a partir dos dados da Prova Brasil 2011, de Marcos Rogério dos Santos, apresentado também em 2013.

Quanto à localidade, a escola estudada nessa pesquisa pertence ao Município de Paulo Lopes, território pertencente à região da Grande Florianópolis, com distância aproximada de 50 quilômetros da capital catarinense e com uma população de 
aproximadamente sete mil habitantes. Paulo Lopes foi instalado como município em 20 de dezembro de 1961 pelo coronel da força militar portuguesa, Paulo Lopes Falcão, daí a origem do nome da cidade; em 21 de dezembro do mesmo ano foi fundado o município, e é nesta data que se comemora o aniversário da cidade (PAULO LOPES, 2016a).

Em relação às instituições de ensino do município, todas são públicas; não há nenhuma instituição privada, seja de Educação Infantil, Ensino Fundamental, Ensino Médio ou Superior. Neste cenário, portanto, Paulo Lopes conta apenas com duas instituições que atendem os Anos Finais do Ensino Fundamental: uma estadual e a referida nesta investigação, que é municipal. Porém, é somente na escola mantida pelo poder público estadual que são oferecidas vagas para o Ensino Médio.

Nesse contexto, os estudantes de Paulo Lopes que concluem o Ensino Médio e que pretendem continuar os estudos, procuram cidades vizinhas que oferecem cursos superiores de graduação, cursos técnicos, etc. Para tanto, a Prefeitura concede Transporte Escolar para o deslocamento desses estudantes para Palhoça, São José e Florianópolis.

Dentre os bairros do município de Paulo Lopes está o bairro Penha, onde se encontra a Escola Básica Dr. Ivo Silveira localizada na rua Manoel Elizandro da Silveira, instituição a qual abrigava o CAIS. A primeira escola do bairro Penha surgiu em 1936, mas foi somente em 1963 que a Escola Básica Dr. Ivo Silveira foi fundada em uma área de 200m², contando apenas com duas salas de aula construídas de madeira. Anos mais tarde a escola precisou ser transferida de local, onde ficou por mais quatro anos. Após esse período, novamente ela precisou passar para outro terreno, no qual permanece até hoje. Todas essas áreas em que a escola foi construída eram doadas por moradores do bairro. Quanto à origem do nome da escola a mesma é resultado de uma homenagem ao governador de Santa Catarina, Ivo Silveira (TURMA 401 e 402, 2010).

Segundo o Projeto Político-Pedagógico da E. B. Dr. Ivo Silveira, a escola possui uma área de $1500 \mathrm{~m}^{2}$ e conta com diversos espaços, dentre eles: dez salas de aula, refeitório, cozinha, espaço de lavação, salas de depósito, sala de informática, biblioteca, sala de vídeo, sala de educação física, sala dos professores, sala de apoio pedagógico, sala de assistência técnica pedagógica, secretaria escolar, banheiros, quadra de esportes polivalente coberta e parque infantil.

A escola funciona nos período matutino e vespertino, atendendo a Educação Infantil, Ensino Fundamental e até meados de 2017 o CAIS. Quanto ao apoio pedagógico, ele visa o atendimento às crianças de $2^{\circ}$ ano ao $6^{\circ}$ ano que apresentam algum tipo de dificuldade de aprendizagem. Para que essas crianças tenham o atendimento extraclasse, ou seja, o apoio 
no período inverso ao das suas aulas regulares, o professor regente ou a psicóloga da Prefeitura Municipal devem prescrever relatórios a fim de encaminhá-las para que esse acompanhamento extraclasse se efetive.

A Rede Municipal de Educação decidiu em sua Proposta Curricular o estabelecimento de quatro eixos norteadores para o seu trabalho educacional: 1: Atenção à diversidade - Currículo para a Diversidade, Educação Intercultural, Inclusão das Pessoas com Deficiência, Avaliação Inclusiva; 2: Educação Ambiental; 3: Inclusão Digital; 4: Desenvolvimento da Capacidade Criadora.

Estes eixos, bem como toda a Proposta, são resultados das discussões dos docentes e gestores que foram acontecendo durante os cursos de formação continuada. Como está ressaltado na própria Proposta Curricular, "esses eixos têm por pretensão ser o alicerce para a qualificação do processo educativo da Rede Municipal” (PAULO LOPES, 2008, p. 12).

No que se refere ao primeiro eixo da Proposta Curricular da Rede Municipal de Paulo Lopes, o mesmo aborda como último subtítulo a "Avaliação Inclusiva". Nesse aspecto é considerada a contextualização como forma de intervenção educativa, uma vez que por meio desta é possível diagnosticar a diversidade e promover um melhor desempenho no que se refere à aprendizagem dos estudantes. A Proposta Curricular apresenta três pontos definidos como "pilares teórico-metodológicos da avaliação inclusiva". São eles: Atenção à diversidade, a qual novamente é tratada como necessidade para a percepção de que os sujeitos possuem ritmos e estilos de aprendizagem diferentes, portanto a avaliação deve acontecer primando por essas características; critérios para avaliação, que por sua vez define que não existem fórmulas ou receitas a serem seguidas, cada qual variando de acordo com o seu público e contexto; e, por último, as técnicas e instrumentos avaliativos, que defendem a ideia de que a:

[...] adoção de técnicas adequadas e de instrumentos tão bem elaborados que possibilitem realmente o conhecimento individual e forneçam as informações necessárias para o docente, mediante sua prática, possa intervir de acordo com as especificidades e com o propósito de melhorar a aprendizagem de cada aluno. (PAULO LOPES, 2008, p. 29-30).

Já o PPP da escola teve a sua última atualização em 2015 e é possível notar que alguns dados ainda estão desatualizados, como no caso do tópico "Distribuições de Turma" que ainda se remete ao ano de 2012. É possível perceber que a escola entende o PPP como um eixo norteador que possibilita o trabalho em conjunto e paralelo das diferentes áreas do conhecimento. Ainda para evidenciar sua importância é citado no documento as concepções da escola em relação ao PPP:

Cidadania em Ação; Revista de Extensão e Cultura, Florianópolis (SC), v. 3, n. 2, jul./dez.2019. 
Neste sentido, discutimos e definimos concepções para um Projeto Político e Pedagógico de base humanista, contrário ao de mercado, com concepção da sociedade real, que questione o porquê das coisas e do mundo serem assim. De base democrática, com responsabilidade socioambiental, com princípios de inclusão, cidadania, respeito, participação e solidariedade. (PAULO LOPES, 2016b, p. 3)

Podemos evidenciar que a Progressão Parcial está definida pelos seguintes critérios: por promoção para alunos com aproveitamento, na própria escola; por transferência para alunos procedentes de outras escolas; por distorção série-idade; por avaliação dos conhecimentos pelo corpo docente e demais autoridades da instituição.

Portanto, entendendo que o Projeto CAIS não se inseria no ensino regular, devia também ter uma proposta diferenciada. Desse modo, o Programa possuía um documento norteador, cuja estrutura se configurava da seguinte forma: Introdução; Justificativa; Objetivos (geral e específicos); Base legal; Organização e Encaminhamento Pedagógico; Diretrizes para Avaliação; Critérios Parecer Descritivo; Responsabilidades dos Alunos e Alunas; Quadro Resumo; Documentos Bases; Referências Bibliográficas.

Nesse momento, é de grande relevância que a nossa reflexão seja direcionada para alguns pontos importantes que norteiam a problematização dessa pesquisa. Assim, os principais questionamentos são: qual é o tipo de estudante que estava se formando no Ensino Fundamental da E. B. Dr. Ivo Silveira por meio do projeto CAIS? Qual era o nível de preparação que esses estudantes possuíam para dar continuidade em seus estudos? Qual era a concepção curricular prevista para essas classes de correção de fluxo? Como se dava a formação continuada dos professores em atividades específicas para as turmas de correção de fluxo da Rede Municipal de Paulo Lopes? Quais eram os limites e as possibilidades da proposta de correção de fluxo desse município?

A partir das problematizações acima, Veiga (2002, p.1) nos esclarece que o Projeto Político-Pedagógico (PPP) deve ser entendido como “a própria organização do trabalho pedagógico da escola como um todo”. O PPP, então, constitui-se como a organização da escola e se dá a partir de um processo democrático de decisões que busca romper com as relações competitivas e a descentralização almejando encontrar a autonomia e qualidade. Ele ainda deve ser fundado nos princípios de igualdade de condições para acesso e permanência na escola, deve propiciar qualidade formativa para todos e a gestão democrática como princípio constitucional, bem como a liberdade e a valorização do magistério. Pensar o PPP também envolve pensar o currículo e sua relação com a avaliação.

As perguntas aqui levantadas não se esgotam nessa breve investigação. Importa-nos levarmos outros/as pesquisadores/as a refletirem a respeito do objeto em tela, e talvez 
instigá-los/as a investigar temas/objetos semelhantes; afinal, igualmente como num PPP, este trabalho não deve ser considerado algo pronto e acabado, mas sim, um objeto de constante reflexão e reformulação.

\section{O PROCESSO DE AVALIAÇÃO E DE FORMAÇÃO CONTINUADA NA PERSPECTIVA DO PROGRAMA CAIS}

O processo avaliativo insere-se em uma discussão histórica sobre a exigência de um processo formal de avaliação enquanto proposta pedagógica e de controle sobre as escolas e os professores, ou seja, historicamente a avaliação é vista como uma forma de autenticar o trabalho realizado em sala de aula e, infelizmente, na maioria das vezes o que está em jogo é a promoção ou o atraso, e não a forma pela qual o sujeito aprende.

Podemos evidenciar esta lógica nas avaliações em larga escala em nível nacional, como por exemplo, o $\mathrm{SAEB}^{7}$, sistema este que engloba a $\mathrm{ANEB}^{8}, \mathrm{ANRESC}^{9}$ e $\mathrm{ANA}^{10}$. Além desses mecanismos de avaliação, na mesma perspectiva temos o ENEM - Exame Nacional do Ensino Médio, que por sua vez tem como objetivo "avaliar o desempenho do estudante ao fim da educação básica, buscando contribuir para a melhoria da qualidade desse nível de escolaridade" (INEP, 2016).

\footnotetext{
7 “O Sistema de Avaliação da Educação Básica (SAEB) tem como principal objetivo avaliar a Educação Básica brasileira e contribuir para a melhoria de sua qualidade e para a universalização do acesso à escola, oferecendo subsídios concretos para a formulação, reformulação e o monitoramento das políticas públicas voltadas para a Educação Básica. Além disso, procura também oferecer dados e indicadores que possibilitem maior compreensão dos fatores que influenciam o desempenho dos alunos nas áreas e anos avaliados”. (INEP, 2016). 8 “Abrange, de maneira amostral, alunos das redes públicas e privadas do país, em áreas urbanas e rurais, matriculados na $4^{\mathrm{a}}$ série $/ 5^{\circ}$ ano e $8^{\mathrm{a}}$ série $/ 9^{\circ}$ ano do Ensino Fundamental e no $3^{\circ}$ ano do Ensino Médio, tendo como principal objetivo avaliar a qualidade, a equidade e a eficiência da educação brasileira. Apresenta os resultados do país como um todo, das regiões geográficas e das unidades da federação". (INEP, 2016).

9 "Trata-se de uma avaliação censitária envolvendo os alunos da $4^{\mathrm{a}}$ série $/ 5^{\circ}$ ano e $8^{\mathrm{a}}$ série $/ 9^{\circ}$ ano do Ensino Fundamental das escolas públicas das redes municipais, estaduais e federal, com o objetivo de avaliar a qualidade do ensino ministrado nas escolas públicas. Participam desta avaliação as escolas que possuem, no mínimo, 20 alunos matriculados nas séries/anos avaliados, sendo os resultados disponibilizados por escola e por ente federativo". (INEP, 2016).

10 “Avaliação censitária envolvendo os alunos do $3^{\circ}$ ano do Ensino Fundamental das escolas públicas, com o objetivo principal de avaliar os níveis de alfabetização e letramento em Língua Portuguesa, alfabetização Matemática e condições de oferta do Ciclo de Alfabetização das redes públicas”. (INEP, 2016).
} 
Sendo um dos elementos que compõem o processo de ensino e aprendizagem, a avaliação toma um papel importante nesse meio, uma vez que é a ferramenta mais utilizada para verificar o nível de aprendizagem dos estudantes e como eles estão se apropriando dos conhecimentos apresentados em sala de aula. Em contrapartida, a avaliação foi criada num contexto de formalização excessiva do controle do processo de aprendizagem e, com isso, é possível perceber as permanências desta visão seletiva/meritocrática que as práticas avaliativas tradicionais possuem.

Um exemplo claro destas permanências é a construção de fichas comportamentais classificatórias no final de um semestre ou de um ano, o que equivale às anotações de avaliação utilizando pareces descritivos padronizados ou escalas comparativas, tais como: se a criança atingiu, não atingiu; muitas vezes, poucas vezes; não apresentou, todas elas realizadas no âmbito da Educação Infantil. Hoffmann (2011) aborda esse tema mais direcionado para a Educação Infantil, mas muito do que a autora defende está relacionado também com os demais níveis de ensino, por isso tomamos sua obra para fundamentar esse trabalho.

Desse modo, podemos notar que não é somente na Educação Infantil que a ferramenta de avaliar por meio de fichas classificatórias é utilizada; evidenciamos a presença desses meios avaliativos também no Projeto do Programa CAIS, no qual este mecanismo avaliativo é chamado de Parecer Descritivo, conforme tabela abaixo:

\section{Tabela 1:}

Parecer Descritivo:

Aluno (a):

\begin{tabular}{|l|l|l|l|}
\hline PARECER DESCRITIVO & mínimo & Razoável & máximo \\
\hline 1- Interação & & & \\
\hline 2- Envolvimento e Interesse & & & \\
\hline 3- Aprendizagem & & & \\
\hline 4- Respeito e Regimento & & & \\
\hline 5- Atitude Coletiva & & & \\
\hline 6- Mudanças Significativas & & & \\
\hline 7- Leitura & & & \\
\hline 7.1- Escrita & & & \\
\hline 7.2- Oralidade & & & \\
\hline 8- Habilidades Matemáticas & & & \\
\hline 9- Habilidades Artísticas & & \\
\hline
\end{tabular}

Fonte: Projeto Político Pedagógico do Programa Classe de Aprendizagem para Inserção Social, 2007. Nesse parecer, o docente avalia o educando conforme os critérios, estabelecidos na 
primeira coluna, em "mínimo", "razoável" e "máximo"; ele apenas assinala o nível que o/a estudante atingiu, conforme sua ponderação. Ora, será que essa ação realmente é descritiva, como é intitulado o "parecer"? Avaliar o estudante em "mínimo", "razoável" e "máximo" dará conta de considerar as especificidades de seu processo de aprendizagem? Uma vez que as possibilidades e limitações do sujeito estudante do CAIS já não foram acolhidas no ensino formal regular, essa seria a melhor forma de avaliá-lo/a a fim de considerar suas singularidades? Essa perspectiva avalia o nível de aprendizagem do estudante ou avalia o próprio estudante, reforçando os estigmas que ele já recebeu no ensino regular?

Esta prática muitas vezes acaba sendo um instrumento de seleção e exclusão dentro da escola por se tratar de classificar o aluno, comparando o seu desenvolvimento com os demais. Corroborando com essa ideia, Vasconcellos (2002, p. 3) ressalta que "a simples existência da avaliação classificatória acaba por desviar a atenção do professor [...]: passa a ficar preocupado em definir 'o quanto o aluno merece' e não mais em 'o que é preciso para que o aluno aprenda mais e melhor"”.

Divergindo dessa concepção tradicional de avaliação, é importante que o professor tenha conhecimento da necessidade de intervir na dificuldade do estudante através de uma avaliação diagnóstica que leve em conta as peculiaridades dele, ou de qualquer outra estratégica capaz de identificar os conhecimentos e experiências que o sujeito já apresenta, visando uma mediação oportuna e que pretenda investigar a sua singularidade.

Avaliar, então, envolve as percepções, os sentimentos, a interpretação do educador e, principalmente, a reflexão dele sobre as ações educativas desenvolvidas com os estudantes, facilitando o replanejamento de sua ação docente, o que mais tarde lhe proporcionará subsídios para o alcance de suas finalidades pedagógicas. Observar e julgar não leva a avaliação a um princípio mediador; é imprescindível ao educador observar e refletir sobre as ações e pensamentos dos educandos, neste caso "o professor é o mediador nesse processo e a avaliação enquanto ação se realiza à medida que ele intervém" (HOFFMANN, 2011, p.55).

Já Luckesi (2000, p. 2) defende a ideia de que "avaliar um educando implica, antes de tudo, acolhê-lo no seu ser e no seu modo de ser, como está, para, a partir daí, decidir o que fazer”. Ou seja, o processo de avaliação da aprendizagem precisa antes de tudo começar pelo ponto do acolhimento. Não obstante, o autor ainda ressalta a ideia que além do ato de acolher, a avaliação requer dois processos articulados e que não podem se dissociar que são o diagnosticar e o decidir. O primeiro se remete aos outros dois estágios, que são a constatação do estado do objeto/sujeito a ser avaliado e a qualificação, ou seja, a atribuição 
de uma qualidade deste objeto/sujeito. Depois do diagnóstico, o próximo período é o da decisão, a qual remete à questão: o que fazer com o objeto/sujeito avaliado?

Temos ciência de que não é tão fácil, especialmente nos processos aligeirados deformação continuada em serviço de redes educacionais como a de Paulo Lopes/SC, que se objetive como política pública uma qualificação formativa que prime pela educação integral, e que a mesma não seja ofertada apenas como cumprimento legal/normativo.

\section{CONSIDERAÇÕES FINAIS}

Levando-se em consideração os aspectos observados nessa pesquisa, percebemos que o problema da repetência e da evasão escolar não é algo novo; esses percalços vêm fazendo parte do cenário educacional desde que as instituições públicas de educação surgiram no Brasil. Pior do que saber que esses problemas eclodiram é ter a noção de que eles ainda fazem parte do cotidiano escolar.

Com isso, após várias discussões entre diferentes fóruns (disputas pela hegemonia entre a sociedade civil e a sociedade política) e diferentes perspectivas aí presentes, foi criada a Lei 9.394/1996, que estabeleceu as Diretrizes e Bases para a Educação Nacional; através dela assegurou-se a possibilidade de as escolas oferecerem um "caminho alternativo", que não fosse o Ensino Regular de Ensino, para aqueles estudantes, cuja trajetória escolar estivesse atrasada ou com sucessivas repetências. Logo, as instituições de ensino iniciaram os movimentos de adesão aos programas de Correção de Fluxo. Porém, a partir dos estudos neste trabalho, percebemos que as discussões sobre o sistema de ensino e as políticas educacionais relacionadas à Correção de Fluxo não estão surtindo mudanças significativas e concretas para reverter o quadro da reprovação. Por mais que haja políticas que deem suporte a esse problema, essas ainda são insuficientes para solucioná-los, visto que não são suficientemente asseguradas pelo Estado.

Dado o exposto em relação aos documentos obtidos para a análise da Rede Municipal de Ensino de Paulo Lopes, constatamos que há a necessidade de reestruturá-los, em razão de que as necessidades educacionais estão a todo o momento se alterando; o que poderia ser determinante no ano em que os documentos foram organizados pode não ser mais nos dias atuais. Uma Proposta Pedagógica, cujo ano de elaboração é 2007 não contempla as necessidades atuais da Classe e muito menos dos estudantes. O público-alvo do CAIS em 2007 não é o mesmo de 2008, 2009 e dos demais anos, por isso, vê-se a importância de a Proposta Pedagógica do CAIS, bem como da E. B. Dr. Ivo Silveira, ser estruturada 
regularmente, de acordo com as exigências/demandas dos estudantes dos respectivos anos.

Além disso, chegamos ao entendimento de que os docentes desses programas acabam tendo uma formação continuada em serviço restrita sobre a área específica da Correção de Fluxo ou da Educação de Jovens e Adultos, o que torna o processo de ensino-aprendizagem cada vez mais fragilizado e inviável para que os estudantes continuem sua trajetória escolar. Porém, esta pesquisa nos permitiu encontrar documentos legais que prometiam a garantia de política municipal de formação inicial e continuada para Paulo Lopes, como a Lei ${ }^{\circ} 1.648$ de 25 de agosto de 2015 que aprovou o Plano Municipal de Educação - PME. Este Plano tinha como sua décima terceira meta (PAULO LOPES, 2016b, p.382):

\begin{abstract}
Garantir, em regime de colaboração entre a União, o Estado e o Município, no prazo de um ano de vigência deste Plano, política municipal de formação inicial e continuada, com vistas à valorização dos profissionais da educação, assegurando que todos os professores da educação básica e suas modalidades possuam formação específica de nível superior, obtida em curso de licenciatura na área de conhecimento em que atuam, bem como a oportunização, pelo poder público, de periódica participação em cursos de formação continuada.
\end{abstract}

Portanto, a oferta de formação continuada a todos os profissionais da Educação Básica do município estudado ainda era uma promessa naquele contexto. $\mathrm{O}$ passo seguinte seria a reivindicação do monitoramento contínuo da Secretaria Municipal de Educação, da Comissão de Constituição, Legislação e Justiça da Câmara de Vereadores e do Conselho Municipal de Educação de Paulo Lopes em relação para o cumprimento da meta de número treze, bem como do restante do PME.

Outro aspecto percebido é que as práticas vigentes de verificação da aprendizagem por meio de fichas não dão conta de amparar os estudantes na apropriação do conhecimento; o instrumento de avaliação disposto na Proposta do CAIS está ainda associado à ideia de classificação e exclusão.

Por fim, em relação à inserção social e profissional que é anunciada no Programa, prometendo dar suporte aos estudantes após a conclusão de seus estudos, vimos que esta pouco ou quase nunca aparece na prática. E ainda, sem a pretensão de concluir, mas apenas para refletirmos: alguma vez os estudantes com sucessivas repetências estiveram fora da sociedade (já que entendemos que há uma inclusão social destes jovens, ainda que de forma desigual) para termos que fazer a inserção dos mesmos, como está disposto no título do Programa CAIS? 


\section{REFERÊNCIAS}

ARROYO, M. G. Educação de jovens e adultos: um campo de direitos e de responsabilidade pública. In: SOARES, Leôncio. (Org.). Diálogos na educação de jovens e adultos. São Paulo: Autêntica, 2005. p. 19-50.

BRASIL. Lei no 9.394, de 20 de dezembro de 1996. Lei de Diretrizes e Bases da Educação Nacional. Disponível em: http://www.planalto.gov.br/CCIVIL_03/leis/L9394.htm. Acesso em: 05 abr. 2016a.

BRASIL. Constituição (1988). Constituição da República Federativa do Brasil: promulgada em 5 de outubro de 1988. Disponível em: http://www2.camara.leg.br/atividadelegislativa/legislacao/Constituicoes_Brasileiras/constituicao1988.html/ConstituicaoTextoA tualizado_EC84.pdf. Acesso em: 22 fev. 2016b.

BRASIL. Lei $\mathbf{n}^{0}$ 5.692, de 11 de agosto de 1971. Lei de Diretrizes e Bases da Educação Nacional. Disponível em: http://www.planalto.gov.br/CCIVIL_03/leis/L5692.htm. Acesso em: 22 fev. $2016 \mathrm{c}$.

CAETANO, L. V. C.; DIÓGENES, E. M. N. Projeto político-pedagógico: diálogos intercruzados entre Veiga e Vasconcellos. In: ENCONTRO DE PESQUISA EM EDUCAÇÃO EM ALAGOAS, 5., 2010, Maceió. Anais. Diponível em: http://dmd2.webfactional.com/media/anais/PROJETO-POLITICO-PEDAGOGICODIALOGOS-INTERCRUZADOS-ENTRE-VEIGA-E-VASCONCELLOS.pdf. Acesso em: 12 abr. 2016.

DI PIERRO, M. C. R.; MASAGÃO, V.; JOIA, O. Visões da educação de jovens e adultos no Brasil. Cadernos do CEDES, Campinas, n. 55, p. 58-77, 2001.

DUARTE, C. L. K. Um estudo sobre alunos inseridos no programa de aceleração da aprendizagem. 2005. Trabalho conclusão de curso. UCB. Brasília. Disponível em: http://www.ucb.br/sites/100/103/TCC/22005/CamilaLiraKanashiroDuarte.pdf. Acesso em: 15 jan. 2016.

FERNANDES, C. O. A promoção automática na década de 1950: uma revisão bibliográfica na RBEP. Trabalho apresentado na $24^{\text {a }}$ Reunião Anual da ANPEd. Rio de Janeiro, 2004.

FURINI, Dóris Regina Marroni; DURAND, Olga Celestina da Silva; SANTOS, Pollyana dos. In: LAFFIN, Maria Hermínia Lage Fernandes (Org.). Educação de jovens e adultos e educação na diversidade. Florianópolis: Universidade Federal de Santa Catarina, p. 184$215,2011$.

GRIS, P. C.; TONDIN, C. F.. O Programa Correção de Fluxo frente à superação do Fracasso Escolar. In: Encuentro Latino americano de Profesores de Política Educativa, E56a (1. : 2015: Guarulhos, SP), Seminário Internacional de Questões de Pesquisa em Educação, (2. : 2015: Guarulhos, SP). Anais eletrônicos do I Encuentro Latino americano de Profesores de Política Educativa; II Seminário Internacional de Questões de Pesquisa em 
Educação, 2015. Guarulhos/SP: UNIFESP, 2015. Disponível em: http://www.encuentrorelepe.com.br/down.php?id=1097\&q=1. Acesso em: 28 jan. 2016.

HANFF, B. B.; BARBOSA, R.; KOCH, Z. M. Classes de Aceleração: "Pedagogia" da inclusão ou da exclusão? Ponto de Vista, Florianópolis, n. 3/4, p. 027-046, 2002.

HOFFMANN, J. Avaliação na pré-escola: um olhar sensível e reflexivo sobre a criança. Porto Alegre: Mediação, 2011.

INEP. "Manifesto dos Pioneiros da Escola Nova". Revista brasileira de estudos pedagógicos. - v. 1, n. 1 (jul. 1944). - Brasília: Instituto Nacional de Estudos Pedagógicos, 1944.

INEP. Instituto Nacional de Estudos e Pesquisas Educacionais [online]. Disponível em: http://portal.inep.gov.br/web/saeb/aneb-e-anresc. Acesso em: 07 jun. 2016.

KRAMER, S. Propostas pedagógicas ou curriculares: subsídios para uma leitura crítica. Educação \& Sociedade, v.18, n.60, p.15-37, dez. 1997. Disponível em: http://www.scielo.br/pdf/es/v18n60/v18n60a1.pdf. Acesso em: 23 mar. 2016.

LAFFIN, M. H. L. F. (Org.). Educação de Jovens e Adultos na Diversidade - Livro 2. 1. Ed. Florianópolis: Núcleo de Publicações do CED, 213 p., 2010.

LALLI, V. S. O programa Acelera Brasil. Em aberto, Brasília, v.17, n. 71, p. 145-146, jan. 2000.

LIBÂNEO, J. C. Organização e gestão da escola: teoria e prática. Goiânia: Editora Alternativa, 2004.

LUCKESI, C. C. O que é mesmo o ato de avaliar a aprendizagem? Pátio. Porto alegre: ARTMED. Ano 3, n. 12 fev./abr. 2000. Disponível em: https://www.nescon.medicina.ufmg.br/biblioteca/imagem/2511.pdf. Acesso em: 23 mai. 2016.

MAROCHI, Z. M. L. Projeto de Correção de Fluxo: uma marco referencial na educação do Paraná. Revista Em Aberto: Programas de Correção de Fluxo. Brasília, v. 17, N. 71, p. 134138, jan. 2000.

MENEZES, E. T.; SANTOS, T. H. Verbete Declaração de Salamanca. Dicionário Interativo da Educação Brasileira - Educabrasil. São Paulo: Midiamix, 2001. Disponível em: http://www.educabrasil.com.br/declaracao-de-salamanca/. Acesso em: 23 mar. 2016.

OLIVEIRA, A. C. F. Perfil do profissional que atua com jovens em situação de vulnerabilidade social e ou risco do programa da correção de fluxo da Rede Pública Estadual de Ensino. Orientado por Katarina Grubisic. São José, 2013. 64p. Monografia (Especialização em Educação para a diversidade com ênfase em educação para jovens e adultos) - Instituto Federal de Educação, Ciência e Tecnologia de Santa Catarina, São José, 2013. 
PARENTE, M. M. A.; LÜCK, H. Mecanismos e experiências de correção do fluxo escolar no ensino fundamental. Instituto de Pesquisa Econômica Aplicada. Brasília, 2004. Disponível em: http://www.ipea.gov.br/portal/images/stories/PDFs/TDs/td_1032.pdf. Acessado em: 02 fev. 2016.

PAULO LOPES. Lei $\mathbf{n}^{\mathbf{0}}$ 1.648, de 25 de agosto de 2015. Aprova o Plano Municipal de Educação - PME e dá outras providências. Diário Oficial [dos Municípios de Santa Catarina], Florianópolis, SC, $\mathrm{n}^{\mathrm{o}}$ 1814, 26 ago. 2015, p. 372-384. Disponível em: https://drive.google.com/file/d/0B5-9jJtxVIQST3JJUk9kMlR6YlU/view. Acesso em: 20 jun. 2016b.

PAULO LOPES. Prefeitura Municipal de Paulo Lopes. Histórico do Município, 05 mar. $2016 . \quad$ Disponível em: http://www.paulolopes.sc.gov.br/cms/pagina/ver/codMapaItem/58298. Acesso em: 05 mar. 2016a.

PAULO LOPES. Prefeitura Municipal de Paulo Lopes. Secretaria Municipal de Educação. Projeto Político Pedagógico do Programa Classe de Aprendizagem para Inserção Social. Rede Municipal de Ensino de Paulo Lopes. Paulo Lopes. SME, 2007.

\section{PAULO LOPES. SECRETARIA MUNICIPAL DE EDUCAÇÃO. Plano Municipal de}

Educação de Paulo Lopes. Paulo Lopes. Paulo Lopes: Instituto Sinergia de Extensão e Pós-Graduação, 2008.

PEREIRA, Lílian Alvez; FELIPE, Delton Aparecido; FRANÇA, Fabiane Freire. Origem da Escola Pública Brasileira: A Formação do Novo Homem. Orientado por Analete Regina Schelbauer e Teresa Kazuko Teruya. Maringá, 2006, 20f. Trabalho como uma das exigências para a conclusão da disciplina Escola Pública e Pensamento Educacional na Contemporaneidade do Programa de Pós Graduação em Educação - Linha de Pesquisa Ensino Aprendizagem e Formação de Professores - em nível de mestrado da Universidade Estadual de Maringá, 2006.

PRADO, I. G. A. LDB e Políticas de Correção de Fluxo Escolar. Revista Em Aberto, Brasília, v.17, p.49-56, Jan, 2000.

SANTOS, M. R. Repetência e distorção idade-série nas escolas públicas de Ensino Fundamental de Santa Catarina: um estudo a partir dos dados da Prova Brasil 2011. Orientado por Prof. Dr. Erni José Seibel. Florianópolis, 2013. 24f. Trabalho de Conclusão de Licenciatura (Curso de Ciências Sociais, do Centro de Filosofia e Humanas) Universidade Federal de Santa Catarina, Florianópolis, 2013. Disponível em: https://repositorio.ufsc.br/handle/123456789/105025. Acessado em: 23 jan. 2016.

SCHLINDWEIN, Luciane Maria; PETRI, Claudia Maria. As classes de aceleração e o sucesso escolar - o que faz a diferença. Trabalho apresentado na $24^{a}$ Reunião Anual da ANPEd. Rio de Janeiro, 2004. Disponível em: http://webcache.googleusercontent.com/search?q=cache:WYVmLHtQnXYJ:24reuniao.anp

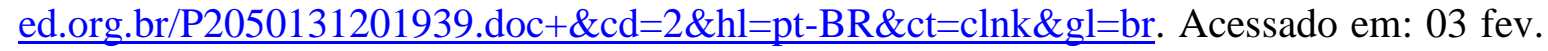
2016. 
TURMA 401 E 402. Trabalho escolar: Resgate Histórico da Escola realizado pelos alunos da 4 $^{\text {a }}$ série do ano de $\mathbf{2 0 1 0}$ da Escola Básica Dr. Ivo Silveira, orientado pelas professoras Jade M. G. Bittencourt da Silveira e Marli Borges Carboni. Paulo Lopes, 2010.

VASCONCELOS, L. S.. Da promoção em massa à progressão continuada: o percurso da promoção escolar no Brasil. In: SEMINÁRIO NACIONAL DE ESTUDOS E PESQUISAS "HISTÓRIA, SOCIEDADE E EDUCAÇÃO NO BRASIL", 7., Campinas SP, 2006.

VEIGA, I. P. A. Projeto Político-Pedagógico, conselho escolar e conselho de classe: instrumentos da organização do trabalho. In: SIMPÓSIO DA ANPAE. UFRGS, 23., Porto Alegre/RS. nov. 2007. Disponível em: http://www.anpae.org.br/congressos_antigos/simposio2007/176.pdf. Acesso em: 14 mar. 2016.

VEIGA, I. P. A. (org) Projeto Político-Pedagógico da Escola: uma construção possível. 14. ed. São Paulo: Papirus, 2002.

VIÉGAS, L. S.; SOUZA, M. P. R. Promoção automática nos anos 1950: a experiência pioneira do Grupo Experimental da Lapa (São Paulo). Educação e Pesquisa, São Paulo, v. 38, n. 2, p. 499-514, abr./jun. 2012. Disponível em: http://www.scielo.br/scielo.php?script=sci_arttext\&pid=S1517-97022012000200015. Acessado em: 29 jan. 2016. 